\title{
Results from Zimbabwe's 2018 Report Card on Physical Activity for Children and Youth
}

\author{
Taru Manyanga, Nyaradzai E. Munambah, Carol B. Mahachi, Daga Makaza, Tholumusa F. Mlalazi, \\ Vincent Masocha, Paul Makoni, Fortunate Sithole, Bhekuzulu Khumalo, \\ Sipho H. Rutsate, and Tonderayi M. Matsungo
}

\section{Introduction}

Physical inactivity, the fourth leading cause of death worldwide, ${ }^{1}$ and childhood obesity ${ }^{2}$ are increasing globally. In low-income countries like Zimbabwe, childhood obesity often co-exists with undernutrition (underweight, wasting, stunting), resulting in an emerging "double burden of malnutrition". ${ }^{2}$ However, there is limited data to accurately assess the extent of these problems among Zimbabwean children. ${ }^{3}$ To better understand and help reduce the unhealthy acceleration of these public health challenges, Zimbabwe is participating in the Global Matrix initiative, ${ }^{4}$ involving 49 countries. This paper summarizes results of Zimbabwe's 2018 Report Card on the physical activity and nutritional status among 5-17 year old children and youth.

\section{Methods}

The 2018 Report Card summarizes data for 10 core physical activity indicators, common to the Global Matrix 3.0 (Overall Physical Activity, Organized Sport and Physical Activity, Active Play, Active Transportation, Sedentary Behaviours, Physical Fitness, Family and Peers, School, Community and Environment, and Government) and two additional indicators (Nutrition and Non-Government). Each of the 12 indicators can be grouped into 1 of 3 categories: Daily Behaviors (Overall PA, Organized Sport and Physical Activity, Active Play, Active Transportation, Physical Fitness, Sedentary Behaviors, Nutrition), Settings and Sources of Influence (Family and Peers, School, Community and Environment), and Strategies and Investments (Government, Non-government).

Data from published, and unpublished studies, and policy documents (with no limits to year-of-publication), reporting on physical activity and related behaviors for 5-17-year-old children were gathered and summarized into a bibliography and an excel spreadsheet. Benchmarks provided by Active Healthy Kids Global Alliance ${ }^{5}$ were used by members of the Report Card Working Group comprising national experts working in various sectors of physical activity viz: academia, government and non-government, to individually assign grades for each indicator. Grades for individual members were collated, and discrepancies noted. The grades for each indicator were converted to a numerical value using a common score. Discrepancies among members' grades were reconciled and the median score was selected for the final grade.

\section{Results and Discussion}

Similar to findings from the 2016 Zimbabwe Report Card ${ }^{4}$ and also to those from countries with comparable Human
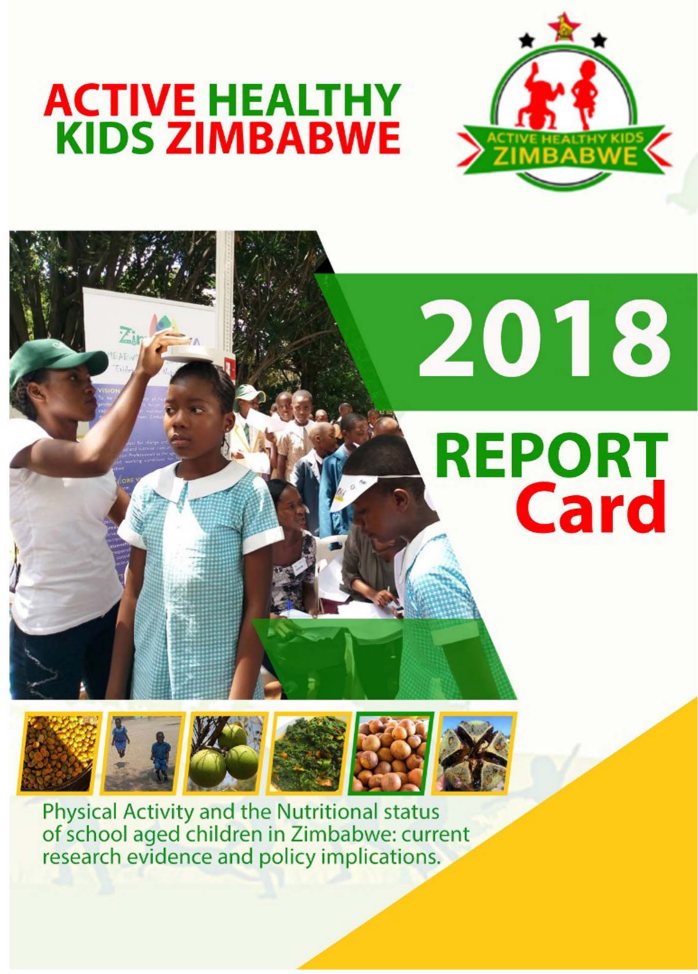

Figure 1 - Zimbabwe's 2018 Report Card cover.

\footnotetext{
Manyanga is with the Healthy Active Living and Obesity Research Group, Children's Hospital of Eastern Ontario Research Institute, Ottawa, Ontario, Canada; and the Faculty of Medicine, School of Epidemiology, Public Health and Preventive Medicine, University of Ottawa, Ottawa, Ontario, Canada. Munambah is with the Rehabilitation Department, University of Zimbabwe, Harare, Zimbabwe. Makaza, Mlalazi, Khumalo, and Rutsate are with the Faculty of Applied Sciences, Department of Sports Science and Coaching, National University of Science and Technology, Bulawayo, Zimbabwe. Mahachi is with the College of Health Sciences, Department of Physiology, University of Zimbabwe, Harare, Zimbabwe. Masocha and Sithole are with the Faculty of Science, Sports Science Department, Bindura University of Science Education, Bindura, Zimbabwe. Makoni is with the Department of Research and Innovation, National University of Science and Technology, Bulawayo, Zimbabwe. Matsungo is with the Institute of Food, Nutrition and Family Sciences (IFNFS), Harare, University of Zimbabwe, Harare, Zimbabwe. Manyanga (tmanyanga@cheo.on.ca) is the corresponding author.
} 
Table 1 Grades and rationales for Zimbabwe's 2018 Report Card

\begin{tabular}{|c|c|c|}
\hline Indicator & Grade & Rationale \\
\hline Overall Physical Activity & $\mathrm{C}+$ & $\begin{array}{l}\text { A combination of expert opinion as well as data from two unpublished studies informed grade } \\
\text { assignment for this indicator. A little over half (59\%) of Zimbabwean children and youth met the } \\
\text { recommended } 60 \text { minutes of daily moderate-to-vigorous physical activity }\end{array}$ \\
\hline $\begin{array}{l}\text { Organized Sport and Physical } \\
\text { Activity Participation }\end{array}$ & $\mathrm{B}$ & $\begin{array}{l}\text { Two studies, ( } 1 \text { published and } 1 \text { unpublished) provided data to inform grading of this indicator. The } \\
\text { data showed that approximately } 67 \% \text { of children and youth participated in organized sport. Some } \\
\text { experts on our panel queried the lack of information on the type of sports and time spent in organized } \\
\text { sporting activities. }\end{array}$ \\
\hline Active Play & $\mathrm{D}+$ & $\begin{array}{l}\text { Only one study, as well as expert opinion informed the grade assignment for this indicator. While the } \\
\text { majority }(47 \%) \text { of children reported spending less than an hour playing outside, only } 35 \% \text { indicated } \\
\text { that they spend more than } 1 \text { hour playing outside before and after school. Given these data and expert } \\
\text { opinion, this indicator was allocated the grade of D+. }\end{array}$ \\
\hline Active Transportation & A- & $\begin{array}{l}\text { Two studies informed the grade for this indicator. The grade did not change from our previous Report } \\
\text { Card because there were no new data since then. Over } 80 \% \text { of children and youth did use active } \\
\text { transport to and from school, but there was some variation between boys and girls as well as between } \\
\text { rural and urban areas. The proportion of boys walking to and from school was lower ( } 79 \% \text { ) compared } \\
\text { with girls ( } 82 \%) \text {. Use of active transport was lower (78\%) among urban and higher ( } 88 \% \text { ) among } \\
\text { rural school children and youth. }\end{array}$ \\
\hline Sedentary Behaviours & $\mathrm{B}$ & $\begin{array}{l}\text { Only one unpublished study informed grade assignment for this indicator. This grade did not change } \\
\text { from the } 2016 \text { Report Card largely because the data used to inform it have not changed since then. } \\
\text { There was considerable debate among experts over what; some argued were unreported high levels } \\
\text { of sedentary behaviors among children. Overall approximately } 75 \% \text { of Zimbabwean children and } \\
\text { youth spend the recommended } \leq 2 \text { hours per day engaged in recreational screen time. About } 15 \% \text { of } \\
\text { children and youth reported watching } 5 \text { or more hours of television the previous day. }\end{array}$ \\
\hline Physical Fitness & Incomplete & $\begin{array}{l}\text { Lack of expert opinion as well as insufficient data to accurately assign a grade for this indicator led us } \\
\text { to conclude that an Incomplete grade would be more appropriate. }\end{array}$ \\
\hline Family and Peers & Incomplete & $\begin{array}{l}\text { Similar to the 2016, Report Card, lack of expert opinion as well as insufficient data to accurately } \\
\text { assign a grade for this indicator led us to conclude that an Incomplete grade would be more } \\
\text { appropriate. }\end{array}$ \\
\hline School & $\mathrm{C}$ & $\begin{array}{l}\text { The primary and secondary schools curricula in Zimbabwe mandate the examination of physical } \\
\text { education. There are dedicated time slots (as is the case with other subjects) throughout the week at } \\
\text { all levels of primary and secondary education. In addition, physical education is taught and examined } \\
\text { as a separate subject at all Institutions of higher education where school teachers are trained. }\end{array}$ \\
\hline Community and Environment & $\mathrm{D}$ & $\begin{array}{l}\text { There is some evidence of infrastructure resuscitation, including a draft policy document, adopted by } \\
\text { the government of Zimbabwe in } 2016 \text { that prioritizes community recreational activities and spaces in } \\
\text { some neighborhoods. Given this level of commitment and progress, but with little concrete evidence } \\
\text { of implementation, the Report Card Working Group awarded a D for this indicator. }\end{array}$ \\
\hline Government & $\mathrm{C}-$ & $\begin{array}{l}\text { Through the Ministries of: Health \& Child Welfare; Sports and Recreation; and Primary and } \\
\text { Secondary Schools, the Government of Zimbabwe has developed and now begun implementing } \\
\text { policies that are meant to increase physical activity among children and youth. All three ministries } \\
\text { have promulgated 5-year strategic plans, with some evidence of allocation of funding to implement } \\
\text { the policies. The new school curriculum which mandates and makes physical education examinable } \\
\text { has now been implemented in primary through to secondary school. The school health policy, In } \\
\text { addition to the policy documents, expert opinion was unanimous that there has been practical } \\
\text { progress for this grade to improve from the D we assigned to it two years ago. }\end{array}$ \\
\hline
\end{tabular}

Development Index ${ }^{6}$ results from the 2018 Report Card show that in general, indicators for daily behaviours had higher grades, compared to the indicators for settings and sources of influence. Grades for overall Physical Activity, Organized Sport and Physical Activity, Active Play, Active Transportation, and Sedentary Behaviours, remained unchanged from the 2016 Report Card, owing to unavailability of new data. Grades for School (C), Community and Environment (D), and Government (C-), improved largely due to policy implementations and commitments made to promoting physical activity ${ }^{7,8}$ and nutritional status 9 among Zimbabwean children and youth. Community infrastructure resuscitation, ${ }^{10}$ and allocation of financial resources were noted as important steps targeting physical activity among children and youth. There was insufficient evidence to accurately assign grades for Physical Fitness and Family and Peers. Two additional indicators, Nutritional Status (B) and Non-Government (INC) were added because of their importance to the Zimbabwean context. The acknowledgement by the Government of Zimbabwe, that malnutrition in all of its forms ${ }^{9}$ is a national public health concern, provides an opportunity for strong advocacy and stakeholder engagement, in support and promotion of improved physical activity and nutrition among Zimbabwean children and youth. Grades assigned, and rationales for each indicator are presented in the Table 1. The cover page (Figure 1) of the Report Card shows an image of the measurement of nutritional status for Zimbabwean children. 


\section{Conclusion}

There are limited and mostly unpublished data on physical activity levels among Zimbabwean children. Overall physical activity levels for Zimbabwean children are lower than desired. Robust research using nationally representative samples, consistent advocacy and stakeholder engagement, including policies that prioritize healthy active living among Zimbabwean children and youth is needed.

\section{References}

1. Kohl HW, Craig CL, Lambert EV, et al. The pandemic of physical inactivity: global action for public health. Lancet. 2012;380(9838): 294-305. doi:10.1016/S0140-6736(12)60898-8

2. Tzioumis E, Adair LS. Childhood dual burden of under- and overnutrition in low- and middle-income countries: A critical review. Food Nutr Bull. 2014;35(2):230-243. doi:10.1177/156482651403500210

3. Manyanga T, Makaza D, Mahachi C, et al. Results from Zimbabwe's 2016 report card on physical activity for children and youth. J Phys
Act Heal. 2016;13(11 suppl 2):S337-S342. doi:10.1123/jpah.20160304

4. Tremblay MS, Barnes JD, González SA, et al. Global Matrix 2.0: Report Card Grades on the Physical Activity of Children and Youth Comparing 38 Countries and the Global Matrix 2.0 Research Team. $J$ Phys Act Heal. 2016;13(suppl 2):343-366. doi:10.1123/jpah.20160594

5. Aubert S., et al. Global Matrix 3.0. J Phys Act Health. 2018.

6. Manyanga T, Barnes JD, Abdeta C, et al. Indicators of physical activity among children and youth in nine countries with low and medium human development index: a Global Matrix 3.0 paper. J Phys Act Health. 2018.

7. Zimbabwe, Ministry of Primary and Secondary Education. Physical Education, Sport and Mass Displays; Junior (Grade 3-7) Syllabus (2015-2022); 2015.

8. Zimbabwe, Ministry of Primary and Secondary Education. Physical Education, Sport and Mass Displays; Form 1-4 (2015-2022).

9. Zimbabwe. Zimbabwe School Health Policy. Harare, Zimbabwe; 2018.

10. Zimbabawe, Ministry of Sport Recreation. The Community Sports Club Program (2017-2022); 2017. 